\section{Synthesis \& Performance Evaluation of Hybrid Cathode Materials for Energy Storage}

\section{Buzaina Moossa ${ }^{b}$, Jeffin James Abrahama, Ramazan Kahraman ${ }^{b}$, Siham Al-Qaradawic, R. A. Shakoora,* \\ ${ }^{a}$ Center for Advanced Materials (CAM), Qatar University (CAM), Doha, Qatar}

${ }^{b}$ Department of Chemical Engineering, Qatar University, Doha, Qatar

'Department of Chemistry \& Earth Sciences, College of Arts and Science, Qatar University, Doha, Qatar

Corresponding author: Shakoor@qu.edu.qa

\section{Introduction}

\section{Abstract}

- A hybrid cathode developed by Li+ substitution for $\mathrm{Na}^{+}$in $\mathrm{Na}_{(2-x)} \mathrm{Li}_{x} \mathrm{FeP}_{2} \mathrm{O}_{7}(\mathrm{x}=0,0.6)$ structure

- Achieved improved thermal stability up to $550^{\circ} \mathrm{C}$

Sub micron sized; phase pure, crystalline material developed with irregular morphology.

- $\mathrm{Na}_{1.4} \mathrm{Li}_{0.6} \mathrm{FeP}_{2} \mathrm{O}_{7}(\mathrm{x}=0.6)$ evaluated with $\mathrm{Na}$ and $\mathrm{Li}$ half cells exhibit promising cyclability.

\section{$\mathrm{Na}_{2-x} \mathrm{Li}_{x} \mathrm{FeP}_{2} \mathrm{O}_{7}(\mathrm{x}=0,0.6)$}

- Both samples $\mathrm{Na}_{2} \mathrm{FeP}_{2} \mathrm{O}_{7}(\mathrm{x}=0), \mathrm{Na}_{1.4} \mathrm{Li}_{0.6} \mathrm{FeP}_{2} \mathrm{O}_{7} \quad(\mathrm{x}=0.6)$, show excellent thermal stability to $550^{\circ} \mathrm{C}$

- $\mathrm{Na}_{1.4} \mathrm{Li}_{0.6} \mathrm{FeP}_{2} \mathrm{O}_{7}$ shows better weight retention when compared to $\mathrm{Na}_{2} \mathrm{FeP}_{2} \mathrm{O}_{7}$

- Paves way for hybrid cathode materials with improved performance.

\section{Why Li Substitution?}

Inadequate performance of Sodium Ion Batteries like slow ion transport, low energy density.

\section{Improve thermal stability}

- Li substitution previously carried out in was $\mathrm{Na}_{1.0} \mathrm{Li}_{0.2} \mathrm{Ni}_{0.25} \mathrm{Mn}_{0.75} \mathrm{O} 2$

This material displayed specific capacity of $95 \mathrm{mAhg}^{-1}$ good cyclic performance and excellent rate capability.

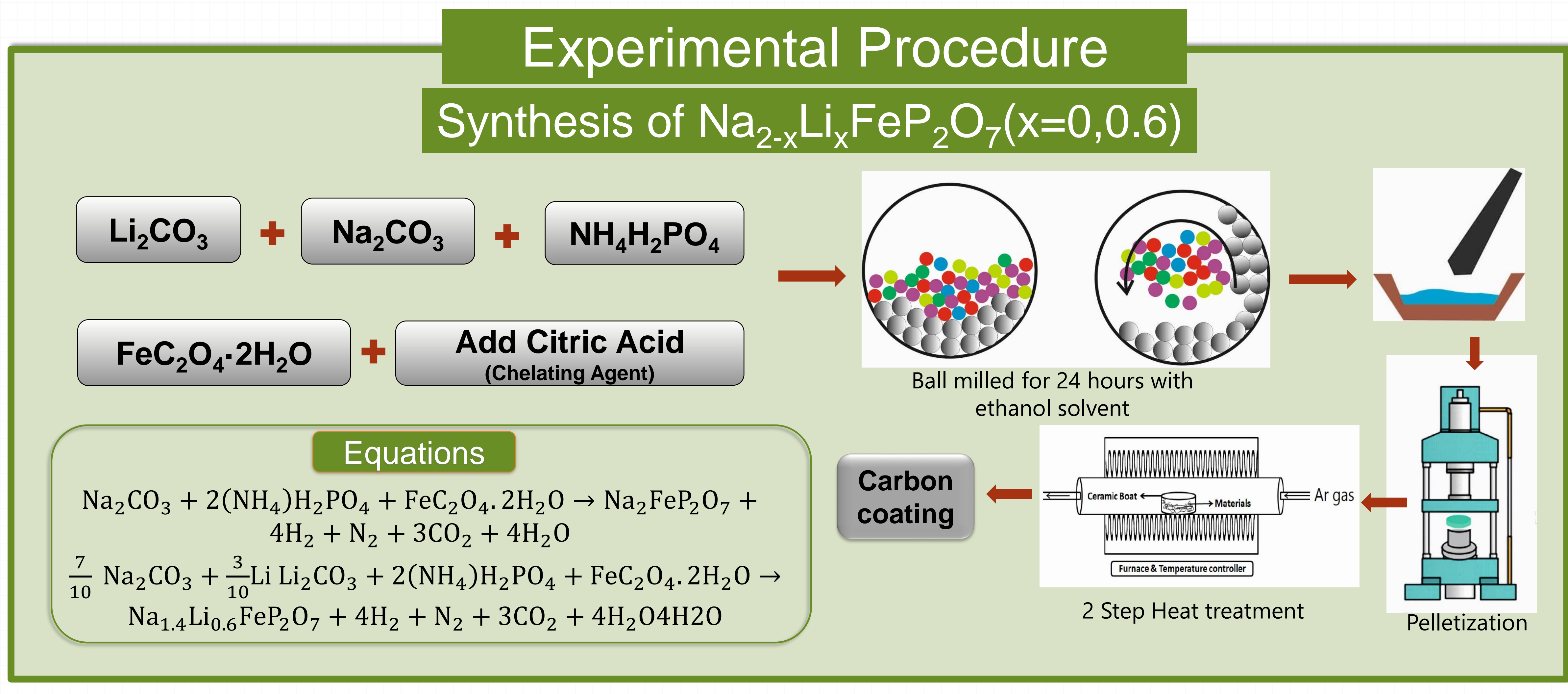

\section{Results \& Discussion}

TGA Analysis

\section{Cyclic Voltammetry curves}

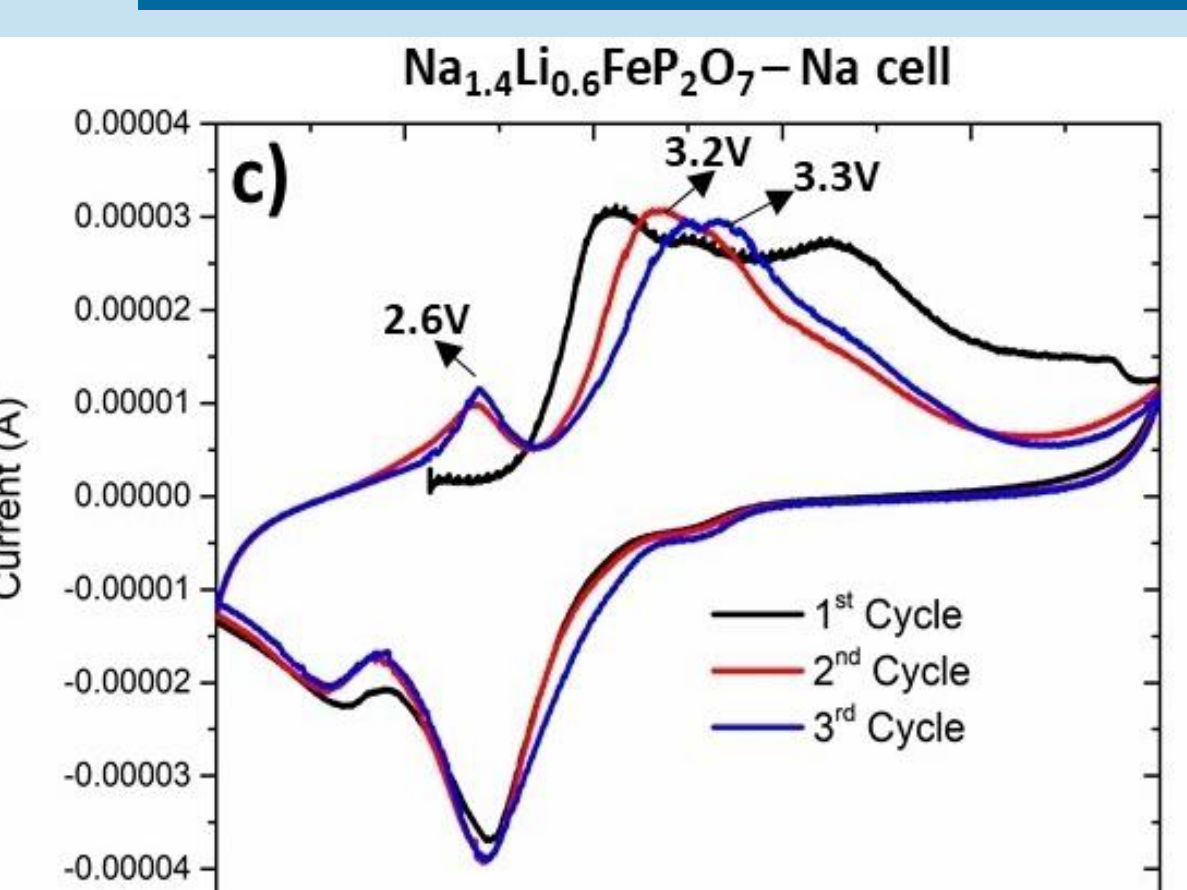

Fig 2-Cyclic voltammetry curves measured at $0.05 \mathrm{mV} / \mathrm{s}$

\section{Charge/Discharge curves}

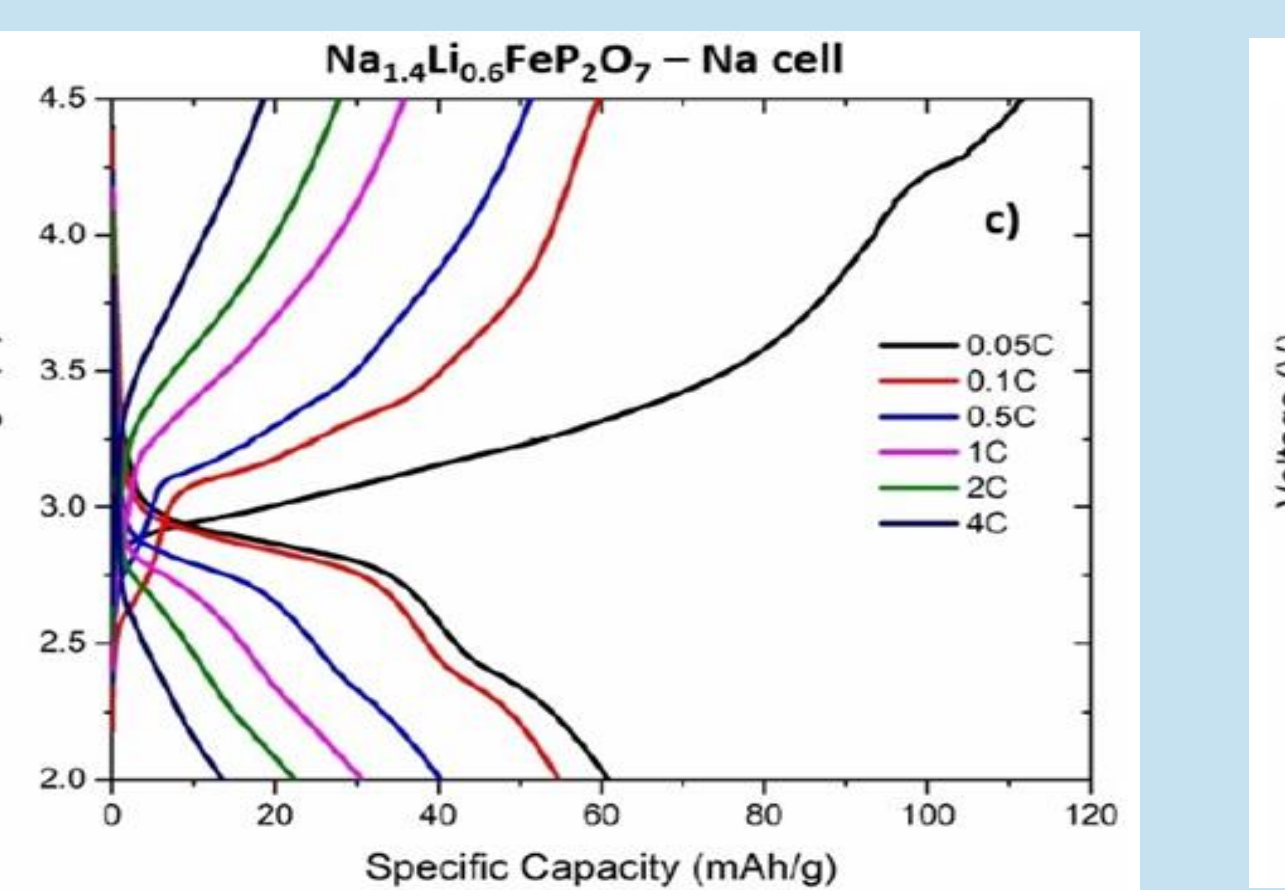

Fig 3- Charge/Discharge curves of $\mathrm{Na}_{1.4} \mathrm{Li}_{0.6} \mathrm{FeP}_{2} \mathrm{O}_{7}$ with $\mathrm{Na}$ and Li cells

\section{GITT Curves}

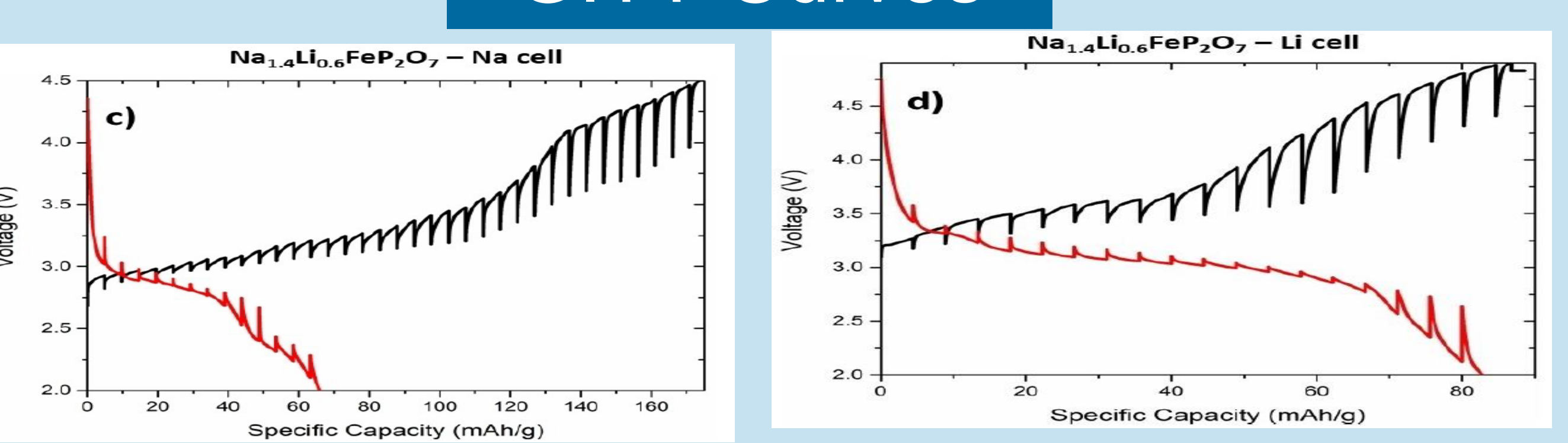

Fig 4- GITT curves for $\mathrm{Na}_{1.4} \mathrm{Li}_{0.6} \mathrm{FeP}_{2} \mathrm{O}_{7}$ with $\mathrm{Na}$ and Li cells

\section{XRD , SEM \& Crystal Structure}

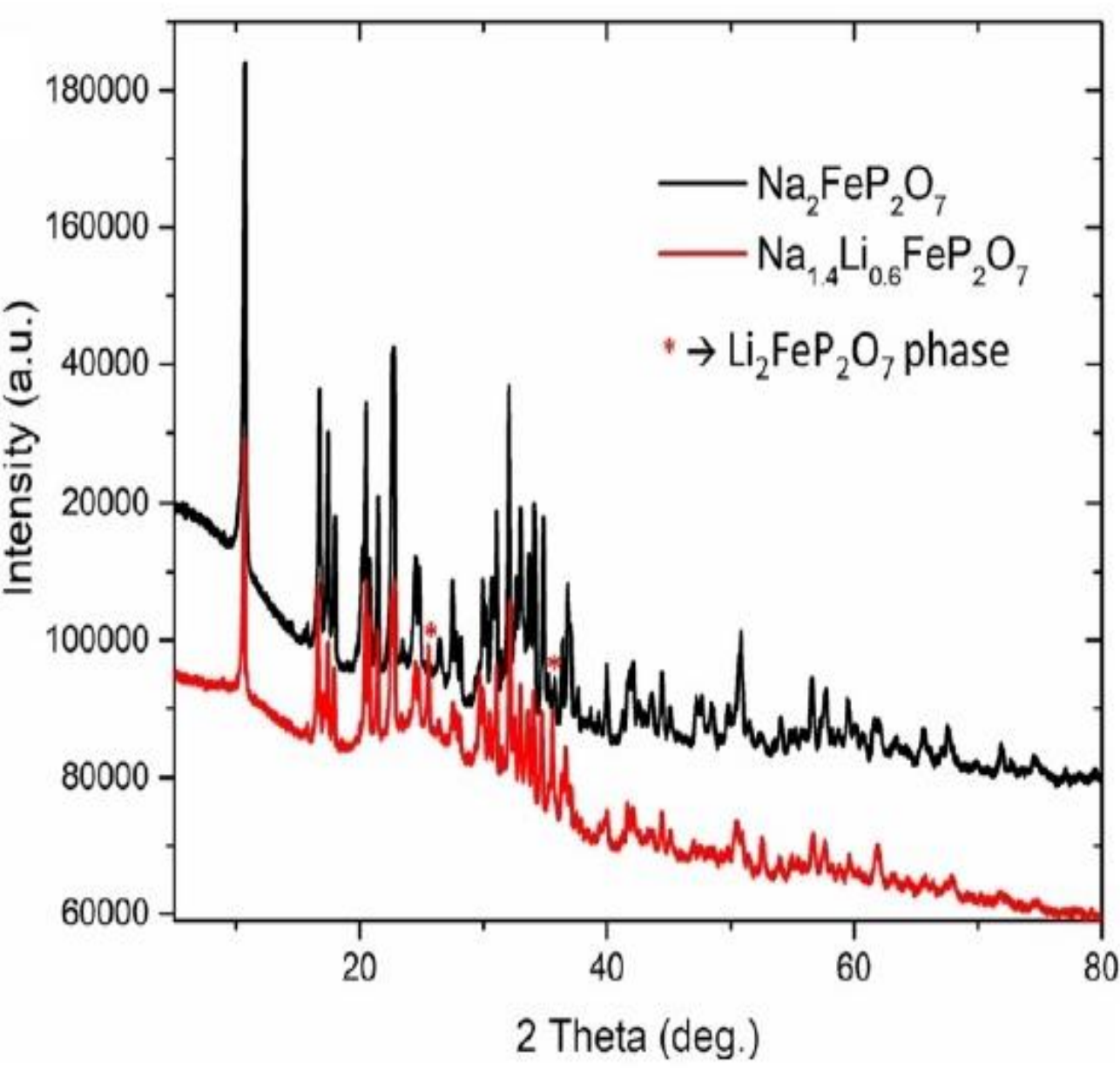

Fig. 5- XRD patterns for $\mathrm{Na}_{2} \mathrm{FeP}_{2} \mathrm{O}_{7}$ and $\mathrm{Na}_{1.4} \mathrm{Li}_{0.6} \mathrm{FeP}_{2} \mathrm{O}_{7}$

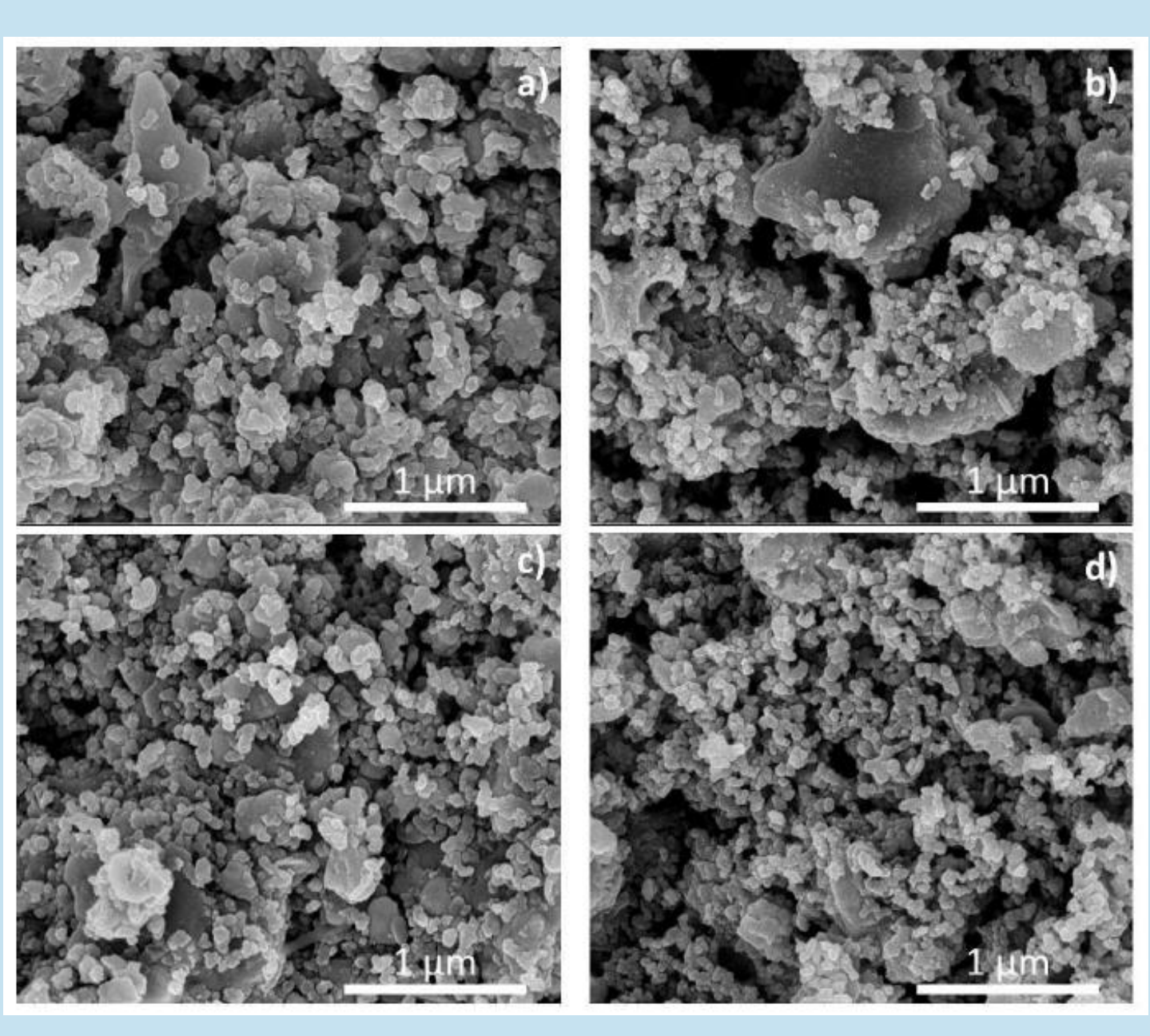

Fig. 6 FE- SEM images; (a)-pristine $\mathrm{Na}_{2} \mathrm{FeP}_{2} \mathrm{O}_{7}$ (b) Pristine $\mathrm{Na}_{14} \mathrm{Li}_{0} \mathrm{FeP}_{2} \mathrm{O}_{7}$ and (c) carbon coated $\mathrm{Na}_{2} \mathrm{FeP}_{2} \mathrm{O}_{7}$ (d) carbon coated $\mathrm{Na}_{1.4} \mathrm{Li}_{0.6} \mathrm{FeP}_{2} \mathrm{O}_{7}$

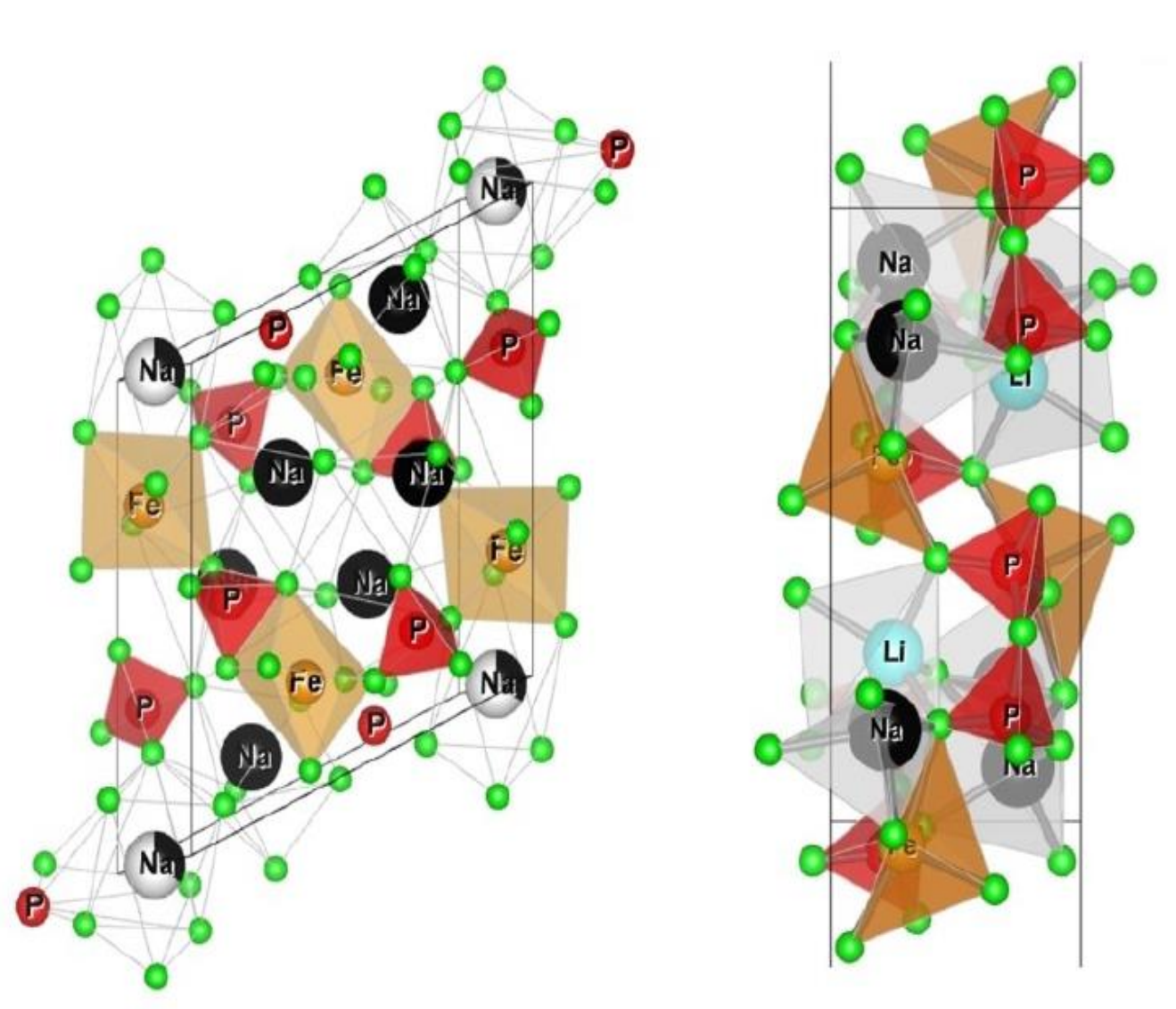

Fig. 7 a- Crystal structure of $\mathrm{Na}_{2} \mathrm{FeP}_{2} \mathrm{O}_{7} ;$ b- Proposed crysta structure of $\mathrm{Na}_{1.4} \mathrm{Li}_{0.6} \mathrm{FeP}_{2} \mathrm{O}_{7}$

Rate capability comparison curve

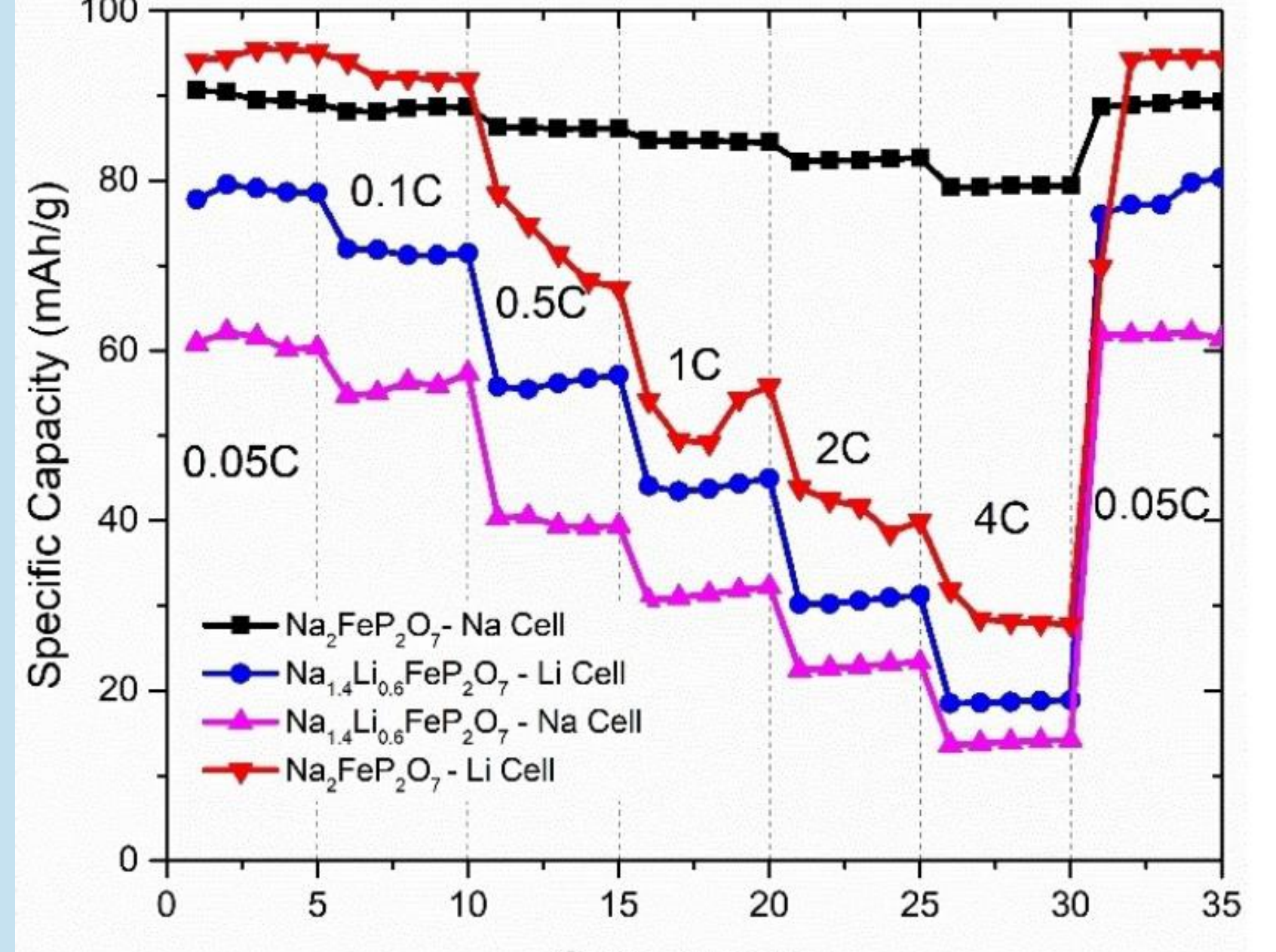

Cycle Number
$\mathrm{Na}_{2} \mathrm{FeP}_{2} \mathrm{O}_{7}$ and

Fig. 8 Rate capacity comparison of $\mathrm{Na}_{2} \mathrm{Fe}_{2} \mathrm{O}$
\[ \mathrm{Na}_{1.4} \mathrm{Li}_{0.6} \mathrm{FeP}_{2} \mathrm{O}_{7} \text { in } \mathrm{Li} \text { and } \mathrm{Na} \text { cells. } \]

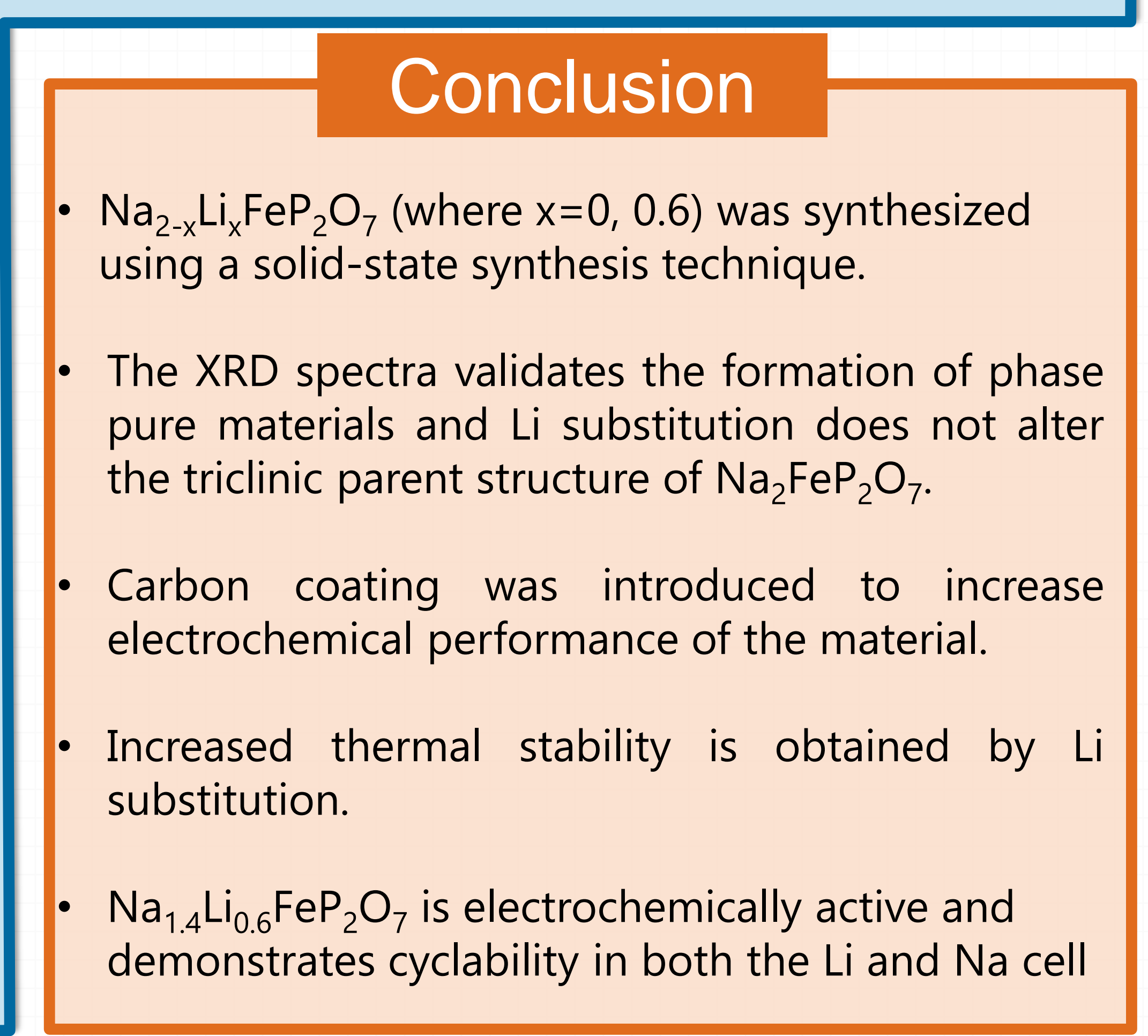

demonstrates cyclability in both the Li and $\mathrm{Na}$ cell 